\title{
HCFC-22 replacement with drop-in and retrofit HFC refrigerants in a two-stage refrigeration plant for low temperature
}

\author{
R. Llopis $^{1}$, E. Torrella ${ }^{2}$, R. Cabello ${ }^{1}$, D. Sánchez ${ }^{1}$ \\ ${ }^{1}$ Jaume I University, Dep. of Mechanical Engineering and Construction, Campus de Riu Sec s/n \\ E-12071, Castellón, Spain \\ ${ }^{2}$ Polytechnic University of Valencia, Dep. of Applied Thermodynamics, Camino de Vera 14, \\ E-46022, Valencia, Spain
}

* Corresponding author: R. Llopis (lllopis@emc.uji.es), Phone: +34 96472 8136; Fax: +34 964728106.

\section{ABSTRACT}

The world community has committed to eliminate the HCFC-22 refrigerant to a series of deadlines according to the agreements taken during the $19^{\text {th }}$ Montreal Protocol meeting in September 2007. This phase-out, which is already in progress in European Countries, has been accelerated in Article 5 countries. Refrigerant manufactures offer different drop-in refrigerants to replace R22 in existing equipment by non-ozone depleting substances in order to be able to make full use of the remaining life of the plants or different retrofit refrigerants, the use of which implies modifications to the existing systems.

This work aims to contribute to the understanding of the implications of the process of R22 substitution, either with drop-in or retrofitting processes, by presenting a theoretical and experimental analysis of the performance of R22, of two drop-in fluids (R422A, R417B) and a retrofit refrigerant (R404A), in a two-stage vapour compression plant over a wide range of 
evaporating temperatures for a fixed condensing temperature of $40^{\circ} \mathrm{C}$. In this communication the main energy parameters, such as cooling capacity and COP are analysed and discussed.

\section{KEYWORDS}

R22; R404A; drop-in; substitute; two-stage system 


\section{NOMENCLATURE}

Nomenclature

\begin{tabular}{|c|c|}
\hline GWP & Global Warming Potential at 100 years \\
\hline$h$ & Enthalpy $\left(\mathrm{kJ} \cdot \mathrm{kg}^{-1}\right)$ \\
\hline$h_{f g}$ & Latent heat of phase change $\left(\mathrm{kJ} \cdot \mathrm{kg}^{-1}\right)$ \\
\hline$\dot{m}$ & Refrigerant mass flow rate $\left(\mathrm{kg} \cdot \mathrm{s}^{-1}\right)$ \\
\hline$q_{0}$ & Specific cooling capacity $\left(\mathrm{kJ} \cdot \mathrm{kg}^{-1}\right)$ \\
\hline$T$ & Temperature $\left({ }^{\circ} \mathrm{C}\right)$ \\
\hline$O D P$ & Ozone Depletion Potential \\
\hline$P_{c}$ & Compressor power consumption (kW) \\
\hline$\dot{Q}_{o}$ & Cooling Capacity (kW) \\
\hline VCC & Volumetric Cooling Capacity $\left(\mathrm{kJ} \cdot \mathrm{m}^{-3}\right)$ \\
\hline$\dot{V}_{G}$ & Compressor displacement $\left(\mathrm{m}^{3} \cdot \mathrm{s}^{-1}\right)$ \\
\hline$w$ & Specific compression work $\left(\mathrm{kJ} \cdot \mathrm{kg}^{-1}\right)$ \\
\hline Greek symbo & \\
\hline$v$ & Specific volume $\left(\mathrm{m}^{3} \cdot \mathrm{kg}^{-1}\right)$ \\
\hline$\varepsilon$ & Subcooler thermal effectiveness \\
\hline$\Delta$ & Increment \\
\hline$\eta_{v}$ & Volumetric efficiency \\
\hline Subscripts & \\
\hline Disc & compressor discharge \\
\hline$H$ & high-compression stage \\
\hline$i$ & intermediate, inlet \\
\hline$k$ & condensing \\
\hline I & saturated liquid \\
\hline$L$ & low-compression stage \\
\hline 0 & evaporating, outlet \\
\hline$s$ & isentropic \\
\hline$S I$ & subcooler liquid line \\
\hline Sv & subcooler vapour line \\
\hline subc & subcooler \\
\hline suc & compressor suction \\
\hline$v$ & saturated vapour \\
\hline
\end{tabular}




\section{INTRODUCTION}

The world community has committed to eliminate the HCFC-22 refrigerant to a series of deadlines according to the agreements taken during the $19^{\text {th }}$ Montreal Protocol meeting in September 2007 (UNEP, 2007). The first refers to European countries, where the Regulation CE-1005/2009 has banned the use of virgin HCFC-22 refrigerant as of $31^{\text {st }}$ December 2009 and only allows the refilling of existing equipment with this refrigerant up to $31^{\text {st }}$ December 2014 if it is recycled. The second is for non-Article 5 countries, which temporal limit is 2020, and finally the 2040 for Article 5 countries. In 2009, this refrigerant, R22, accounted for around 97 per cent of the total amount of HCFC substances used in the refrigeration and air-conditioning sectors (UNIDO, 2009) and it is supposed there will be a shortage of this refrigerant in the near future because the accelerated phase out and the need to refill these systems due to maintenance operations.

Given this situation, the accelerated phase-out and the possible shortage of R22, the commercial refrigeration sector working at low evaporating temperatures has three mechanisms available to eliminate this substance, which are schematized in Figure 1 (Flohr and Meurer, 2009). First, especially for old equipment with remaining life, a drop-in process is recommended. This involves the pure exchange of the refrigerant without any modifications to the refrigerating plant and keeping the existing lubricant oil. The second option is to undertake a retrofitting process. This is understood as an active adaptation of the refrigeration plant to the new refrigerant, which could also entail the replacement of the lubricant oil, the expansion valves and certain other elements of the system. Finally, the last option, although only possible for new equipment, is to design new plants with long-term refrigerants, such as hydrocarbons, ammonia or carbon dioxide. 
Figure 1. Mechanisms and some refrigerant options to substitute R22 in low temperature applications

(Flohr and Meurer, 2009)

In recent years, manufacturers have been developing different chlorine-free drop-in refrigerant mixtures to substitute $\mathrm{R} 22$ in order to exhaust the remaining life of existing refrigerating equipment with only minor modifications (Figure 1). In air conditioning, R422D and R417A are two of the most widely recommended fluids, which were analysed by Fernández-Seara et al.(2010), Rosato et al. (2009), Aprea et al. (2004) and Torrella et al. (2010). In refrigeration at low temperatures, however, two of the most frequently recommended drop-in fluids are R422A and R417B, which correspond to ternary blends of R134a, R125 and different hydrocarbons (iso-butane for R422A and n-butane for R417B) in order to improve the oil mixing behaviour with mineral (MO) lubricants. These last refrigerants were designed in order to match as far as possible the typical properties of R22. However, according to the manufacturers, reductions in capacity and COP can be expected, depending on the refrigeration system. This claim was verified by Arora and Sachdev (2009) using a theoretical approach. Regarding the retrofit R22 substitutes, the options are R404A and R507A, which are also blends of chlorine-free substances, although they are not compatible with MO lubricants. It is therefore necessary to substitute the existing lubricant by polyol-esters (POE) oils. The performance of these last refrigerants, R404A and R507A, is similar (Llopis et al., 2010).

This communication intends to contribute to the experimental research on the process of substituting R22 in existing equipment for low temperature applications by chlorine-free refrigerants. Accordingly, here a theoretical and experimental approach is used to compare the process of substituting R22 by two drop-in substances, R417B and R422A, and by a retrofit refrigerant, R404A. The evaluation was conducted with a two-stage vapour compression plant driven by a compound compressor for a wide range of evaporating and condensing 
temperatures (Llopis et al., 2010; Llopis et al., 2011; Torrella et al., 2009) by comparing the performance of the thermodynamic cycle. In the communication, the main energy parameters, i.e. capacity and COP, are discussed and analysed.

\section{THERMODYNAMIC PROPERTIES OF THE REFRIGERANTS}

Drop-in fluids are designed to match performance characteristics of the refrigerant they are to substitute as closely as possible and the retrofit refrigerants are able to operate in existing plants provided some modifications of different elements in the plants. For the R22 substitute fluids considered in this work (R422A, R417B and R404A), whose composition and main thermodynamic properties are presented in Table 1 and their P-h diagrams in Figure 2, all have a slightly higher pressure for a given phase change temperature than R22, the total compression ratios being similar. One difference is that the substitutes have a temperature glide, which makes them unsuitable for flooded evaporators, although R404A has proved to be applicable (Barreau M. et al., 1996). Another important difference is that there is an important reduction in the latent heat of phase change $\left(h_{f g}\right)$ compared to $\mathrm{R} 22$, which will tend to reduce the capacity provided by the plants. However, the specific volume at suction is reduced for all of them, which will compensate for the reduction in the latent heat of phase change. 


\begin{tabular}{|c|c|c|c|c|c|c|c|}
\hline \multirow{2}{*}{ Composition (\%wt) } & \multirow{2}{*}{$\begin{array}{l}\mathrm{R} 22 \\
\mathrm{R} 22\end{array}$} & \multicolumn{2}{|c|}{$\mathrm{R} 422 \mathrm{~A}$} & \multicolumn{2}{|c|}{ R417B } & \multicolumn{2}{|c|}{ R404A } \\
\hline & & 85.10 & R125 & 79.00 & R125 & 44.00 & R125 \\
\hline & & 11.50 & R134a & 18.25 & R134a & 4.00 & R134a \\
\hline & & 3.40 & R600a & 2.75 & R600 & 52.00 & R143a \\
\hline Molecular weight $\left(\mathrm{g} \cdot \mathrm{mol}^{-1}\right)$ & 86.47 & \multicolumn{2}{|c|}{113.60} & \multicolumn{2}{|c|}{113.07} & \multicolumn{2}{|c|}{97.60} \\
\hline Normal boiling point $\left({ }^{\circ} \mathrm{C}\right)$ & -40.81 & \multicolumn{2}{|c|}{-44.03} & \multicolumn{2}{|c|}{-41.51} & \multicolumn{2}{|c|}{-46.2} \\
\hline Critical temperature $\left({ }^{\circ} \mathrm{C}\right)$ & 96.14 & \multicolumn{2}{|c|}{71.73} & \multicolumn{2}{|c|}{75.18} & \multicolumn{2}{|c|}{71.0} \\
\hline Glide ${ }^{*}\left({ }^{\circ} \mathrm{C}\right)$ & 0 & \multicolumn{2}{|c|}{2.46} & \multicolumn{2}{|c|}{3.43} & \multicolumn{2}{|c|}{0.75} \\
\hline$h_{f g}\left(\mathrm{~T}=-30^{\circ} \mathrm{C}\right)$ & 226.81 & \multicolumn{2}{|c|}{167.44} & \multicolumn{2}{|c|}{172.70} & \multicolumn{2}{|c|}{189.51} \\
\hline$h_{f g}\left(\mathrm{~T}=40^{\circ} \mathrm{C}\right)$ & 166.60 & \multicolumn{2}{|c|}{104.80} & \multicolumn{2}{|c|}{111.17} & \multicolumn{2}{|c|}{120.26} \\
\hline$v_{\text {sat_vapour }}\left(T=-30^{\circ} \mathrm{C}\right)\left(\mathrm{m}^{3} \cdot \mathrm{kg}^{-1}\right)$ & 0.1355 & \multicolumn{2}{|c|}{0.0863} & \multicolumn{2}{|c|}{0.0974} & \multicolumn{2}{|c|}{0.0948} \\
\hline ODP & 0.05 & \multicolumn{2}{|c|}{0} & \multicolumn{2}{|c|}{0} & \multicolumn{2}{|c|}{0} \\
\hline $\mathrm{GWP}_{100 \text { years }}$ & 1810 & \multicolumn{2}{|c|}{3100} & \multicolumn{2}{|c|}{3027} & \multicolumn{2}{|c|}{3921} \\
\hline Safety group (ISO 817:2005) & $\mathrm{A} 1$ & \multicolumn{2}{|c|}{$\mathrm{A} 1$} & \multicolumn{2}{|c|}{$\mathrm{A} 1$} & \multicolumn{2}{|c|}{$\mathrm{A} 1$} \\
\hline
\end{tabular}

*Glide evaluated at saturation temperatures under standard atmosphere pressure (101.325kPa)

Table 1. Physical, environmental and safety characteristics of the refrigerants (Calm and Houranhan, 2007; Lemmon et al., 2007)

Figure 2. Pressure-enthalpy diagram of the R22 and the substitutes

To analyse what the variations in capacity and COP will be when replacing R22 by the substitute fluids, the Refprop database (Lemmon et al., 2007) was used to evaluate the theoretical volumetric cooling capacity (VCC) (Equation 1) and COP (Equation 2) of the twostage vapour compression cycle with a subcooler used in the experimental evaluation (Torrella et al., 2009) (Figure 5). The following assumptions were made: saturated conditions at the exit of the evaporator, condenser and subcooler; ideal compression processes; an inter-stage 
pressure equal to the geometric pressure between condensation and evaporation; and a constant thermal effectiveness of the subcooler of $80 \%$. Where $h_{l}$ and $h_{v}$ are the enthalpies of saturated liquid and vapour at the corresponding temperature, $\varepsilon$ is the thermal effectiveness of the subcooler, $v_{v}$ is the specific volume of saturated vapour, and $w_{s}$ is the specific isentropic compression work at the low and high compression stages.

$$
\begin{aligned}
& V C C=\frac{q_{o}}{\left.v_{v}\right|_{T o}}=\frac{\left.h_{l}\right|_{T k} \cdot(\varepsilon-1)-\left.\varepsilon \cdot h_{l}\right|_{T i}+\left.h_{v}\right|_{T o}}{\left.v_{v}\right|_{T o}} \\
& C O P=\frac{q_{o}}{w_{S}}=\frac{\left.h_{l}\right|_{T k} \cdot(\varepsilon-1)-\left.\varepsilon \cdot h_{l}\right|_{T i}+\left.h_{v}\right|_{T o}}{w_{S, L}+\frac{\left.h_{v}\right|_{T i}+\left.h_{l}\right|_{T k} \cdot(\varepsilon-1)-\left.h_{l}\right|_{T i}}{\left.h_{v}\right|_{T i}-\left.h_{l}\right|_{T k}} \cdot w_{S, H}}
\end{aligned}
$$

The results are presented in Figure 3 for the $V C C$ and in Figure 4 for the $C O P$, for three evaporating levels for a fixed condensing pressure of $40^{\circ} \mathrm{C}$. The percentage reduction of these parameters with regard to the R22 values is also specified.

Figure 3. Theoretical VCC of the ideal two-stage cycle $\left(T_{k}=40^{\circ} \mathrm{C}\right)$

Figure 4. Theoretical COP of the ideal two-stage cycle $\left(T_{k}=40^{\circ} \mathrm{C}\right)$

Regarding the capacity (Figure 3), substitution of R22 with R404A always entails an increase in capacity, with R417B always a reduction and with R422A a slight increase. However, when analysing the theoretical COP (Figure 4), an important reduction is always detected for the three substitute fluids. Nonetheless, all these parameters have been obtained with a theoretical analysis, and no real effects of the compressor have been taken into account. In addition, the refrigerant manufacturers state that the performance of R22 substitutes might differ depending on the refrigeration system being analysed. Accordingly, this evaluation has 
been completed with the experimental analysis of the refrigeration plant, which is detailed in Section 4. 


\section{EXPERIMENTAL FACILITY AND MEASUREMENT TESTS}

\subsection{Experimental test plant}

The experimental plant used for the energy evaluation of the four fluids corresponds to a twostage refrigeration plant, which was initially designed for operation with R22 (Llopis et al., 2010; Torrella et al., 2009). A schematic diagram of the plant is shown in Figure 5 . The compressor is a two-stage $4 \mathrm{~kW}$ semihermetic compound compressor; condenser, evaporator and subcooler are brazed-plate heat exchangers; the evaporating process is controlled by a thermostatic expansion valve with external equalization and the subcooling process with a thermostatic expansion valve.

Figure 5. Schematic diagram of the plant

The plant is fully instrumented with 17 T-type thermocouples $\left( \pm 0.1^{\circ} \mathrm{C}\right), 10$ pressure gauges ( \pm 0.1 bar at low pressure and \pm 0.3 bar at medium and high pressure), two Coriolis mass flow meters ( $\pm 0.22 \%$ of reading) to measure refrigerant mass flow rate, two magnetic volumetric flow meters ( $\pm 0.33 \%$ of reading) to measure volumetric flow rates of secondary fluids and a digital wattmeter ( $\pm 0.5 \%$ of reading) to measure the power consumption of the compressor. The heat transfer rates in the evaporator and condenser were validated with the heat transferred by the secondary fluids, which are a (50/50\% by vol.) water/ethylene-glycol mixture in the evaporator and water in the condenser. The refrigerant properties were evaluated with the Refprop database. 


\subsection{Test procedures and measurements}

The objective of the evaluation was to study the energy performance of the refrigerants when operating at the same evaporating and condensing temperatures, by performing a thermodynamic cycle analysis. Accordingly, the base of comparison recommended by Radermacher and Hwang (2005) was followed. This criterion considered the condensing temperature for a vapour quality in the condenser of $50 \%$ and the evaporating temperature corresponding to the mean enthalpy value in this heat exchanger, that is, the average enthalpy of the refrigerant at the inlet and outlet of the evaporator. Considering this criterion, the four refrigerants were evaluated in a wide range of evaporating temperatures for a fixed condensing temperature of $40^{\circ} \mathrm{C}$ while keeping the compressor speed at its nominal value (1450 rpm). The condensing level was achieved by adjusting the inlet temperature of the cooling water to the condenser. The refrigerants were all tested using POE lubricant oil (viscosity index 120).

Regarding the operation of the plant with the refrigerants, for the drop-in fluids (R422A, R417B) the only modification carried out was the adjustment of the thermal expansion valves in order to obtain the same degree of superheat at the evaporator as that of R22, based on dew-point temperature. For R404A, however, the two R22 expansion valves were replaced by equivalent valves for the new refrigerant. The entire tests with the substitute refrigerants were repeated twice with no appreciable variations in the energy performance. 


\section{ENERGY COMPARISON AND DISCUSSION}

This section presents and analyses the experimental results of the evaluation of R22 with some possible substitutes for low evaporating temperatures, namely, the drop-in fluids R422A and R417B and the retrofit refrigerant substitute R404A. The evaluation covers an evaporating temperature range from -31 to $-17^{\circ} \mathrm{C}$ for a fixed condensing temperature of $40^{\circ} \mathrm{C}$. The discussion focuses on the main energy parameters, i.e., the cooling capacity of the plant $\left(\dot{Q}_{o}\right)$ and Coefficient Of Performance (COP).

\subsection{Cooling Capacity}

The cooling capacity of the two-stage plant can be evaluated with Equation 3, as a product of the refrigerant mass flow rate through the evaporator $\left(\dot{m}_{o}\right)$ and the specific refrigerating effect $\left(q_{o}\right)$. This last parameter can be expressed as the difference in enthalpy at the exit of the evaporator $\left(h_{o, o}\right)$ and at the exit of the condenser $\left(h_{k, o}\right)$ plus the increment in enthalpy due to the liquid subcooling at the subcooler $\left(\Delta h_{\text {subc }}\right)$.

$$
\dot{Q}_{o}=\dot{m}_{o} \cdot q_{o}=\dot{m}_{o} \cdot\left(h_{o, o}-h_{k, o}+\Delta h_{\text {subc }}\right)
$$

If the terms in Equation 3 are analysed, the refrigerant mass flow rate through the evaporator can be expressed with Equation 4, as a quotient of the volumetric efficiency at the low-stage $\left(\eta_{v, L}\right)$ and the specific suction volume at the low-stage $\left(v_{s u c, L}\right)$ multiplied by the compressor's displacement at the low-stage $\left(\dot{V}_{G, L}\right)$ that is a constant parameter for all the refrigerants.

$$
\dot{m}_{o}=\frac{\eta_{v, L}}{v_{s u c, L}} \cdot \dot{V}_{G, L}
$$

The experimental measurements of the refrigerant mass flow rate through the evaporator are presented in Figure 6. As can be observed, with the three substitute refrigerants, there is an important incremental difference in the refrigerant mass flow rate. This difference can be caused by either the specific suction volume or the volumetric efficiency at the low-stage 
(Equation 4). The volumetric efficiency for the three refrigerants, however, remains equivalent (variation less than 10\%). The main reason for this incremental difference being the high reduction in the specific suction volume with the new refrigerants, as presented in Table 1. This incremental difference in the refrigerant mass flow rate will trend to compensate for the reduction in the latent heat of phase change of the new refrigerant in terms of capacity.

Figure 6. Evaporator refrigerant mass flow rate. $\left(T_{k}=40^{\circ} \mathrm{C}\right)$

If the specific refrigerating effect in the evaporator is itemized, as presented by Equation 5, it can be expressed as the difference in enthalpy of the refrigerant at the exit of the evaporator and at the exit of the condenser, plus the increment in enthalpy due to the subcooling process. This last parameter depends on the thermal effectiveness of the subcooler $(\varepsilon)$ and the difference in enthalpy of the saturated liquid at the condensing and inter-stage temperatures.

$$
q_{o}=h_{o, o}-h_{k, o}+\varepsilon \cdot\left(\left.h_{l}\right|_{T k}-\left.h_{l}\right|_{T i}\right)
$$

The enthalpy values are properties of the refrigerant, although the thermal effectiveness of the subcooler depends on the heat transfer coefficients of each refrigerant and could present variations. The experimental measurements are presented in Figure 7 for the specific refrigerating effect and in Figure 8 for the thermal effectiveness of the subcooler.

Figure 7. Specific refrigerating effect $\left(T_{k}=40^{\circ} \mathrm{C}\right)$

Figure 8. Subcooler thermal effectiveness $\left(T_{k}=40^{\circ} \mathrm{C}\right)$ 
As can be analysed in Figure 7, there is an important reduction in the specific refrigerating effect for the three refrigerant substitutes, as expected by their P-h diagram (Figure 2), especially for the drop-in fluids. This term includes the difference in enthalpy due to the subcooling process $\left(\Delta h_{\text {subc }}\right)$, which depends on the thermal effectiveness of the subcooler, which presents important variations (Figure 8). It needs to be highlighted that the thermal effectiveness of the subcooler is reduced for the three substitutes, especially for R404A.

Finally, in Figure 9, the measured capacity is presented for all the refrigerants for a fixed condensing temperature of $40^{\circ} \mathrm{C}$ with a measurement uncertainty of $3.2 \%$. As can be observed, with regard to the performance of $\mathrm{R} 22$, with the drop-in fluids there is an important reduction in capacity, whereas for R404A there is an increase in capacity, especially at high evaporating temperatures. These trends are in agreement with the theoretical analysis presented in Figure 3. For the case of R404A, the reduction in the latent heat of phase change is compensated by the incremental difference in the refrigerant mass flow rate. However, with the drop-in fluids, the increment in the refrigerant mass flow rate is not capable of compensating entirely for this reduction.

Figure 9. Cooling capacity $\left(\mathrm{T}_{\mathrm{k}}=40^{\circ} \mathrm{C}\right)$

\subsection{COP}

Finally, the most important energy parameter of the refrigerating plant is the COP. This can be evaluated with Equation 6, where $\left(\dot{Q}_{o}\right)$ is the cooling capacity of the cycle, which has been analysed previously, and $\left(P_{c}\right)$ is power consumption of the compressor, which is measured in the plant. 


$$
\mathrm{COP}=\frac{\dot{Q}_{o}}{P_{c}}
$$

Figure 10 shows the experimental evolutions of the COP reached by each refrigerant for operation at a fixed condensing temperature of $40^{\circ} \mathrm{C}$, with a measurement uncertainty of $3.3 \%$.

Figure 10. $\operatorname{COP}\left(\mathrm{T}_{\mathrm{k}}=40^{\circ} \mathrm{C}\right)$

As can be observed, there is an important reduction in the COP reached by the refrigerant substitutes, which is greater than that obtained with a theoretical analysis. For operation at an evaporating temperature of $-30^{\circ} \mathrm{C}$ and a condensing temperature of $40^{\circ} \mathrm{C}$, the experimental reductions with regard to $\mathrm{R} 22$ COPs are $-26.0 \%$ for $\mathrm{R} 422 \mathrm{~A},-21.6 \%$ for $\mathrm{R} 417 \mathrm{~B}$ and -20.9 for R404A, whereas the theoretical reductions at the same evaporating and condensing levels were $-14.0 \%$ for R422A, $-12.7 \%$ for R417B and -10.1 for R404A. The reason of these differences, as analysed before, mainly depend on the reduction of the cooling capacity and the increase of the power consumption of the compressor for the drop-in refrigerants, and the increase of power consumption of the compressor for the R404A. 


\section{CONCLUSIONS}

In this work, substitution of R22 with chlorine-free refrigerants has been analysed from an energy point of view. The selected substitutes were two recommended drop-in fluids for low temperature applications, R422A and R417B, and one retrofit refrigerant, R404A. The four fluids were tested in the same test plant, which was designed for operation with R22, over a wide range of evaporating temperatures for a fixed condensing temperature of $40^{\circ} \mathrm{C}$.

The experimental measurements showed that when using any of the substitute fluids there is an important incremental difference in the refrigerant mass flow rate through the plant, which in some cases would make it necessary to readjust the expansion valves of the system.

Regarding the energy performance of R22 substitutes, it must be highlighted that an important reduction in the capacity has been measured when using the drop-in fluids R422A and R417B, whereas, for the retrofit refrigerant R404A the capacity is enhanced to an important degree. Regarding the COP of the plant, the reduction in COP with any of the tested fluids is important and is greater than the values predicted by a theoretical analysis. This fact must be seriously considered if R22 is going to be replaced. It needs to be remarked that the comparison of the refrigerants analysed in the paper was performed under a thermodynamic cycle analysis, hence, if the performance is analysed using external loads, the behaviour may vary. 


\section{ACKNOWLEDGEMENTS}

The authors are indebted to the Spanish Ministry of Education and Science (CTM2008-06468C02-02/TECNO) and to the Spanish Ministry of the Environment and Rural and Marine Affairs (200800050084716) for their economic support for the present work. 


\section{REFERENCES}

Aprea, C., Mastrullo, R., Renno, C., 2004. An analysis of the performances of a vapour compression plant working both as a water chiller and a heat pump using R22 and R417A. Applied Thermal Engineering 24, 487-499.

Arora, A., Sachdev, H.L., 2009. Thermodynamic analysis of R422 series refrigerants as alternative refrigerants to HCFC22 in a vapour compression refrigeration system. Int. J. Energy Res. 33, 753-765.

Barreau M., Macaudiere S., Weiss P., Joubert M., 1996. R-404A in industrial refrigeration application for R-502 and HCFC-22 replacement, System with recirculationtype evaporator, International Conference on Ozone Protection Technologies, Washington 41 DC (USA).

Calm, J.M., Houranhan, G.C., 2007. Refrigerant data update. Heat/Piping/Air Cond Eng 79(1), $50-64$.

Fernández-Seara, J., Uhía, F.J., Diz, R., Dopazo, J.A., 2010. Vapour condensation of R22 retrofit substitutes R417A, R422A and R422D on CuNi turbo C tubes. International Journal of Refrigeration 33, 148-157.

Flohr, F., Meurer, C., 2009. HCFC phase out - How to find the best solution? in: V Spanish and III Iberian Congress of Refrigeration. CYTEF-2009, Castellón, Spain.

Lemmon, E.W., Huber, M.L., McLinden, M.O., 2007. REFPROP, NIST Standard Reference Database 23, v.8. National Institute of Standards, Gaithersburg, MD, U.S.A.

Llopis, R., Torrella, E., Cabello, R., Sánchez, D., 2010. Performance evaluation of R404A and R507A refrigerant mixtures in an experimental double-stage vapour compression plant. Applied Energy 87, 1546-1553.

Llopis, R., Torrella, E., Cabello, R., Sánchez, D., Larumbe, J.A., 2011. HCFC-22 replacement with HFC drop-in refrigerants in refrigeration plants., in: International Institute of Refrigeration, I. (Ed.), The 23rd IIR International Congress of Refrigeration, Prague, Czech Republic. .

Radermacher, R., Hwang, Y., 2005. Vapor compression heat pumps with refrigerant mixtures. CRC Press, Taylor \& Francis, NW.

Rosato, A., Mauro, A.W., Mastrullo, R., Vanoli, G.P., 2009. Experiments during flow boiling of a R22 drop-in: R422D adiabatic pressure gradients. Energy Conversion and Management 50, 2613-2621. 
Torrella, E., Cabello, R., Sánchez, D., Larumbe, J.A., Llopis, R., 2010. On-site study of HCFC-22 substitution for HFC non-azeotropic blends (R417A, R422D) on a water chiller of a centralized HVAC system. Energy and Buildings 42, 1561-1566.

Torrella, E., Llopis, R., Cabello, R., Sanchez, D., 2009. Experimental Energetic Analysis of the Subcooler System in a Two-Stage Refrigeration Facility Driven by a Compound Compressor. HVAC\&R Res. 15, 583-596.

UNEP, 2007. 19th Meeting of the Parties to the Montreal Protocol on Substances that Deplete the Ozone Layer, Montreal. In: http://ozone.unep.org/Meeting_Documents/mop/19mop/MOP-19-7E.pdf.

UNIDO, 2009. Preparing for HCFC phase-out: Fundamentals of uses, alternatives, implications and funding for Article 5 countries.

http://www.unido.org/fileadmin/user_media/Publications/Pub_free/Preparing_for_HCFC _phaseout.pdf (May, 2010). Vienna. 


\section{FIGURES}

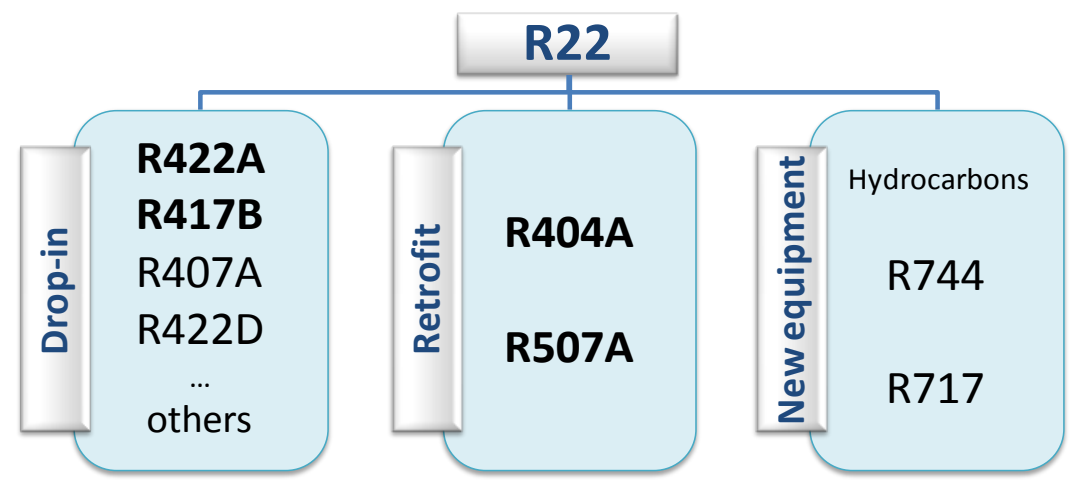

Figure 11. Mechanisms and some refrigerant options to substitute R22 in low temperature applications

(Flohr and Meurer, 2009)

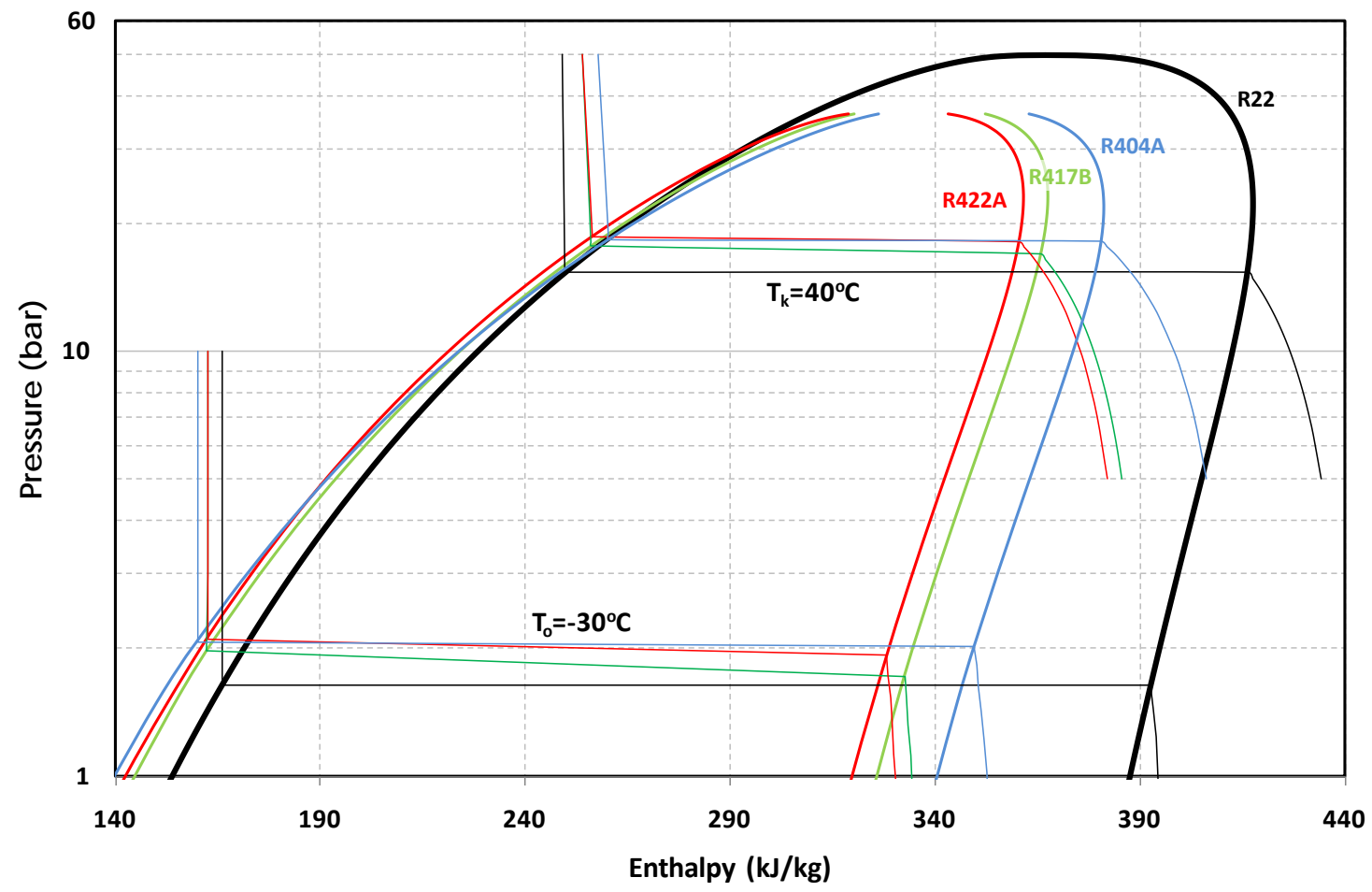

Figure 12. Pressure-enthalpy diagram of the R22 and the substitutes 


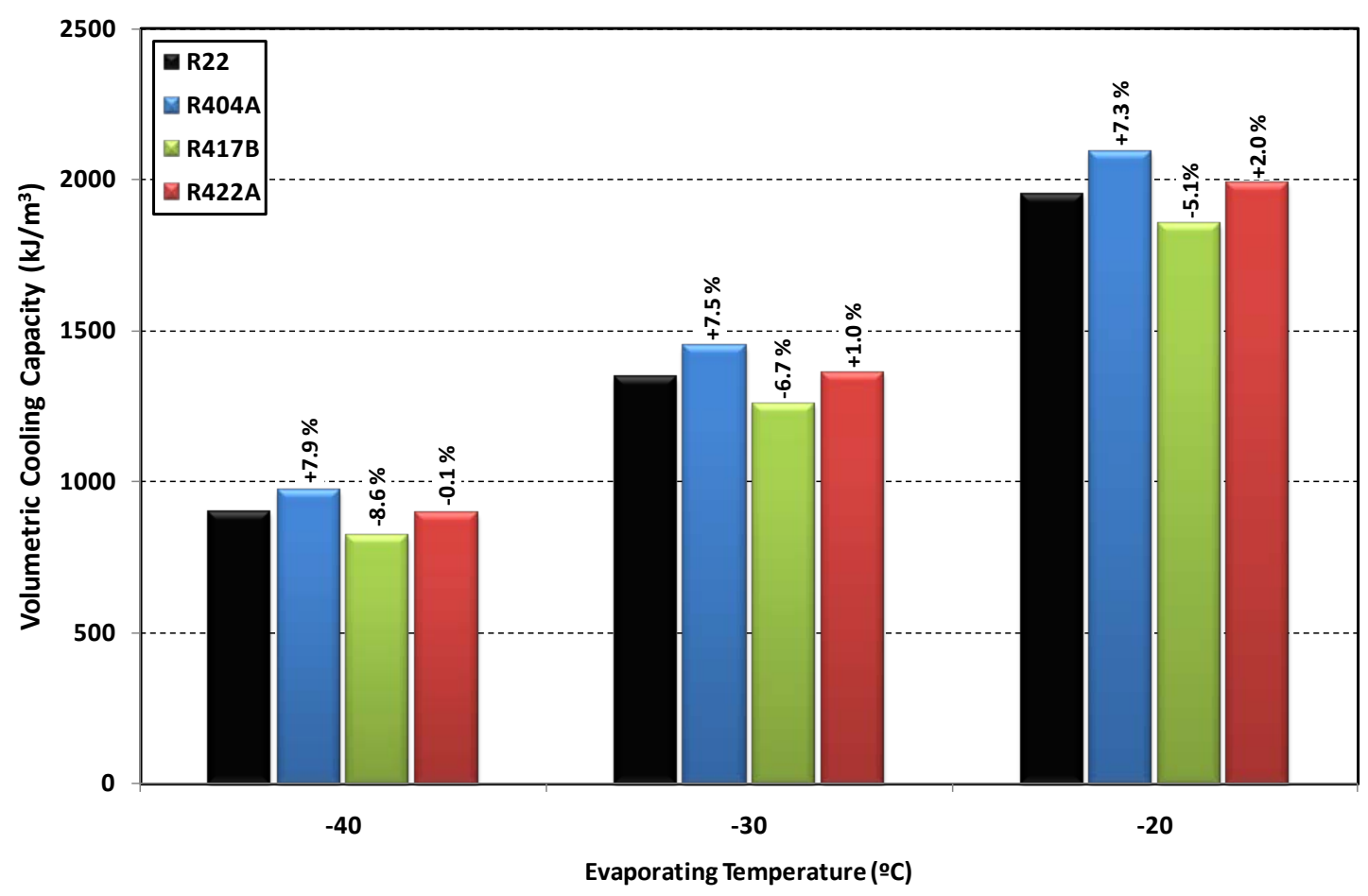

Figure 13. Theoretical VCC of the ideal two-stage cycle $\left(T_{k}=40^{\circ} \mathrm{C}\right)$

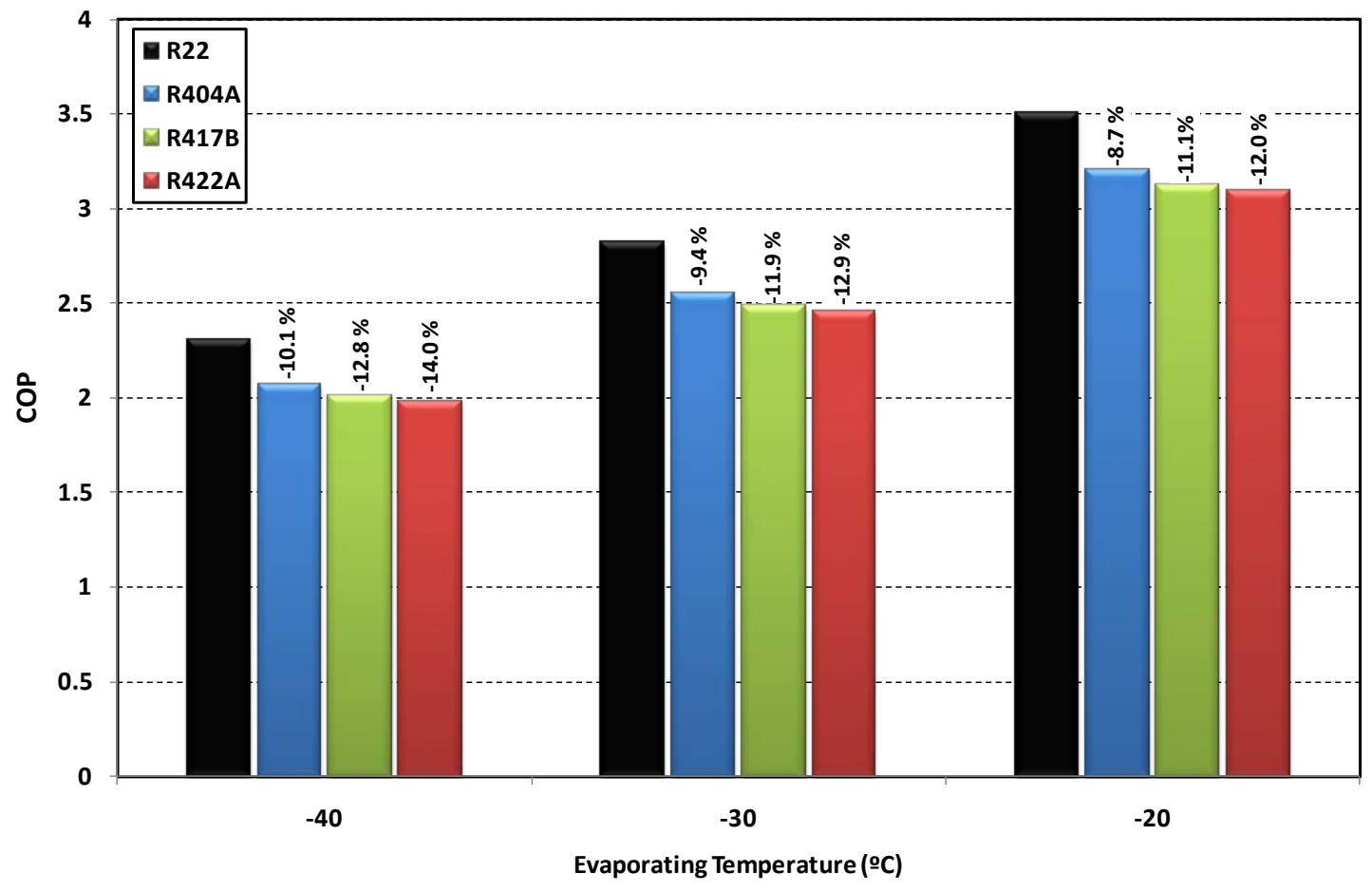

Figure 14. Theoretical COP of the ideal two-stage cycle $\left(T_{k}=40^{\circ} \mathrm{C}\right)$ 


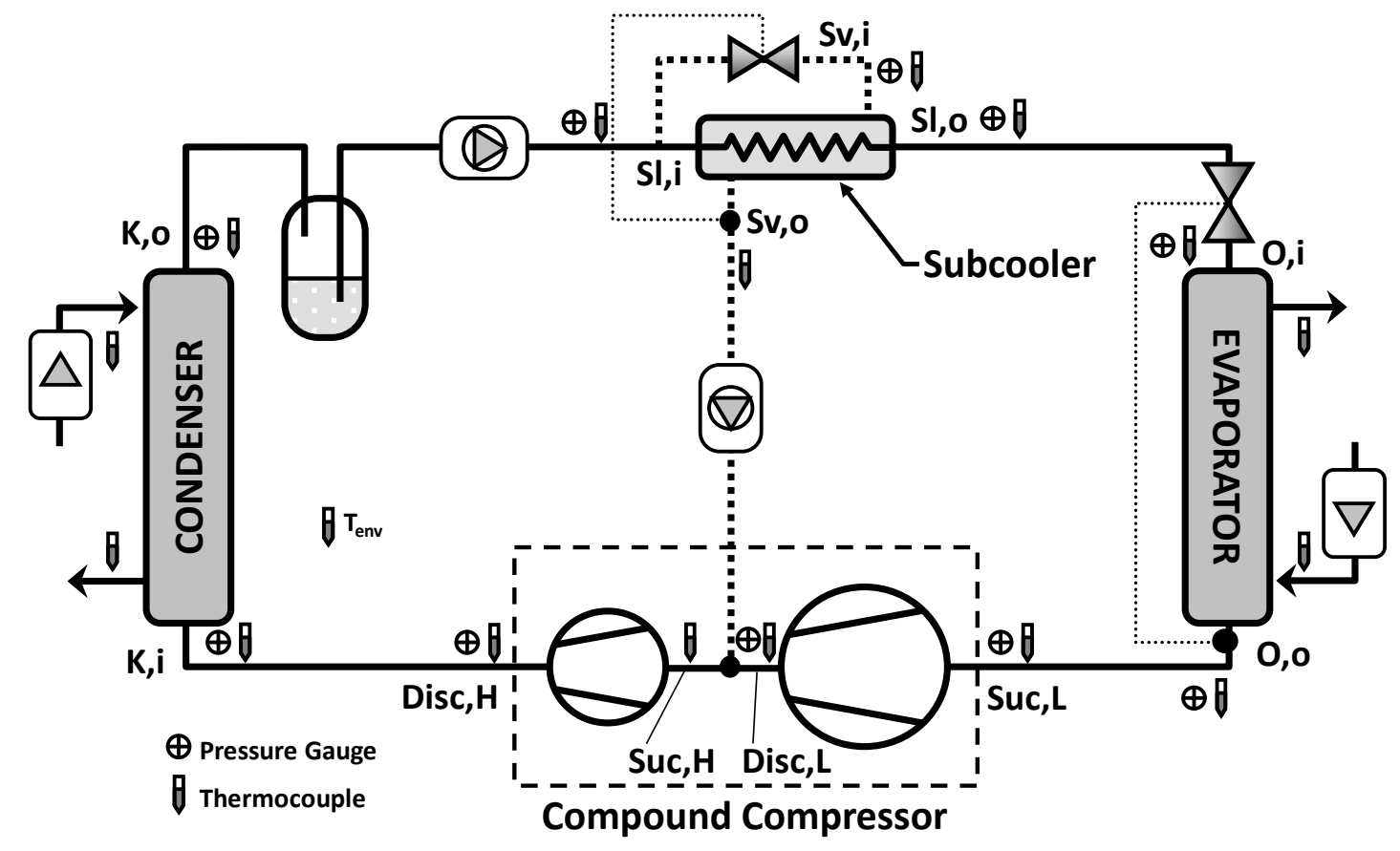

Figure 15. Schematic diagram of the plant

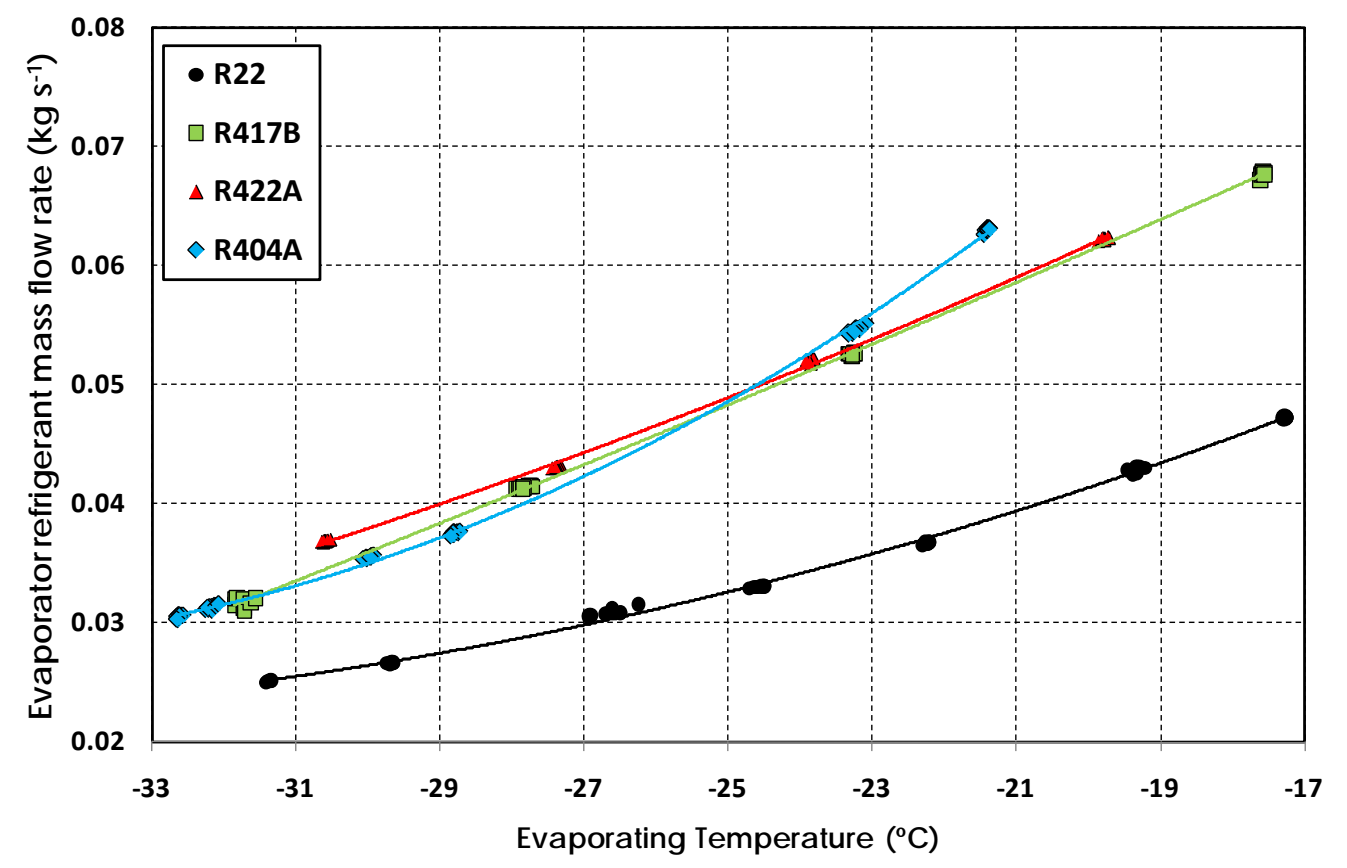

Figure 16. Evaporator refrigerant mass flow rate. $\left(T_{k}=40^{\circ} \mathrm{C}\right)$ 


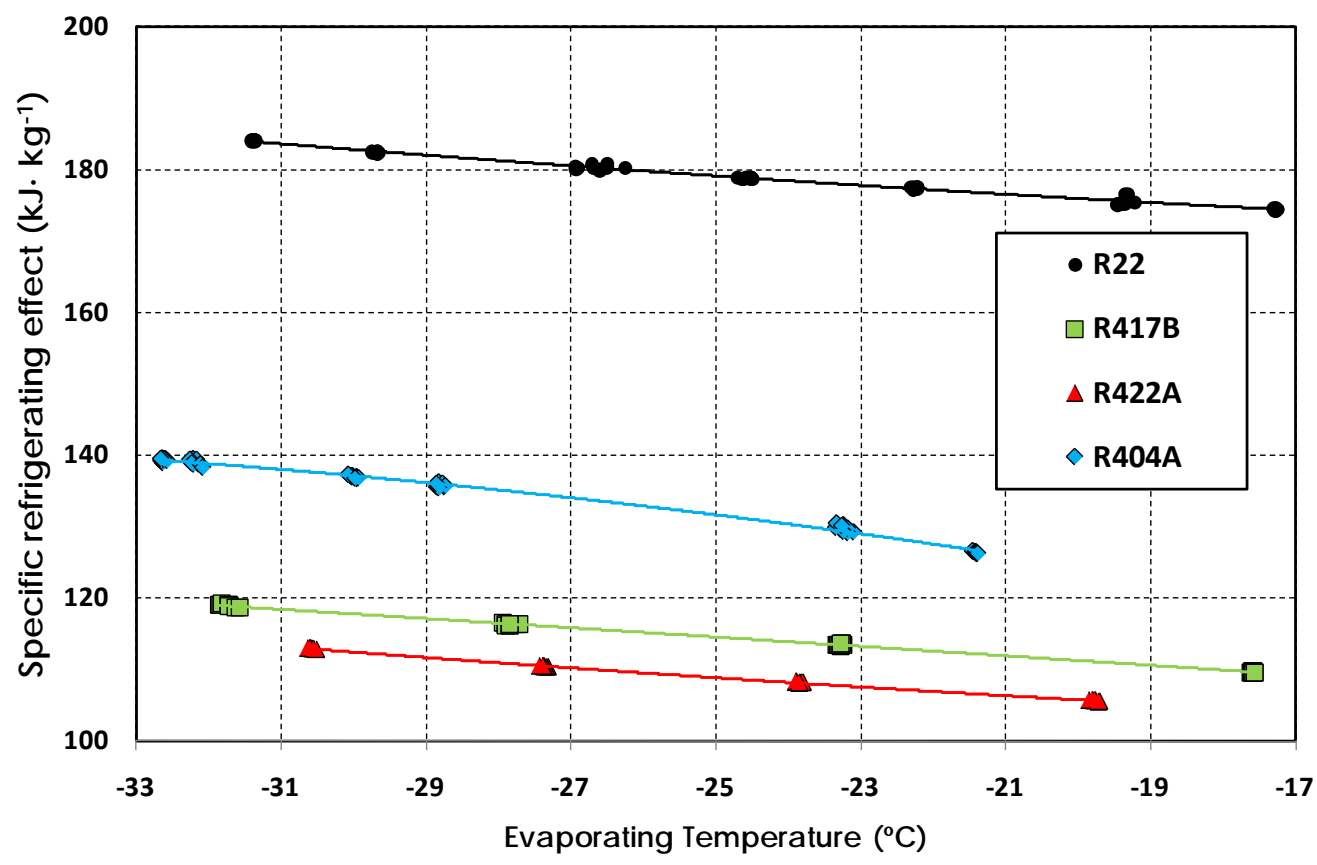

Figure 17. Specific refrigerating effect $\left(T_{k}=40^{\circ} \mathrm{C}\right)$

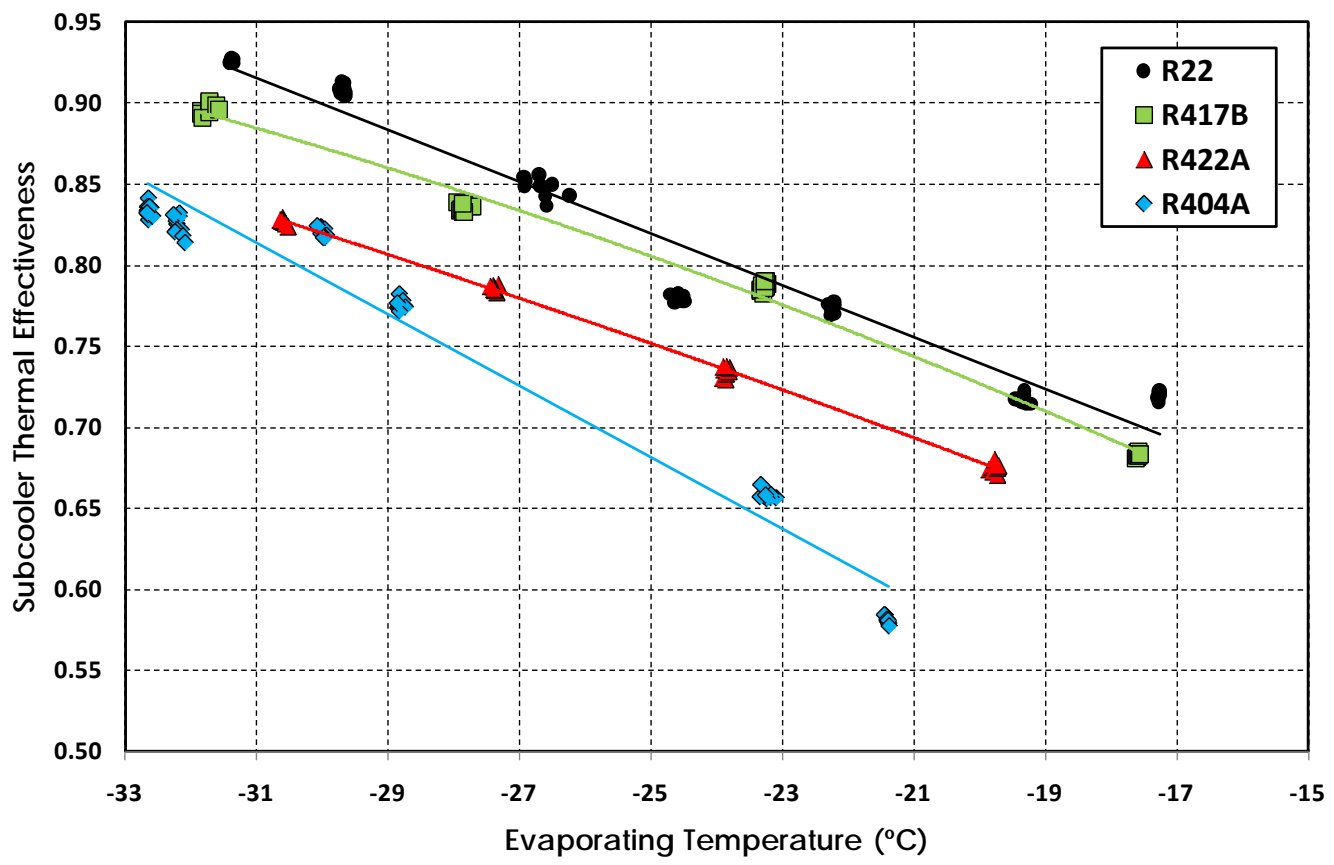

Figure 18. Subcooler thermal effectiveness $\left(T_{k}=40^{\circ} \mathrm{C}\right)$ 


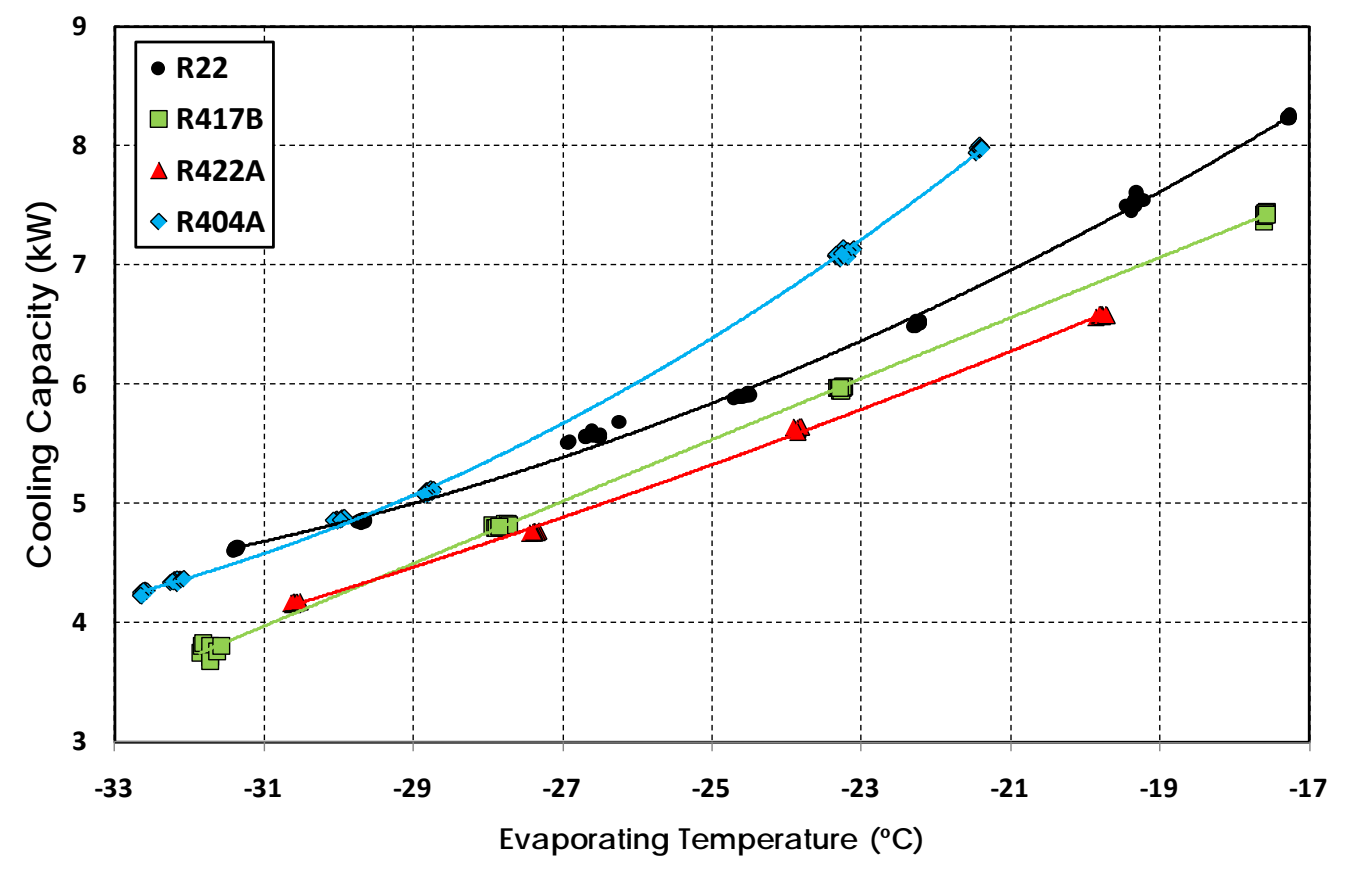

Figure 19. Cooling capacity $\left(T_{k}=40^{\circ} \mathrm{C}\right)$

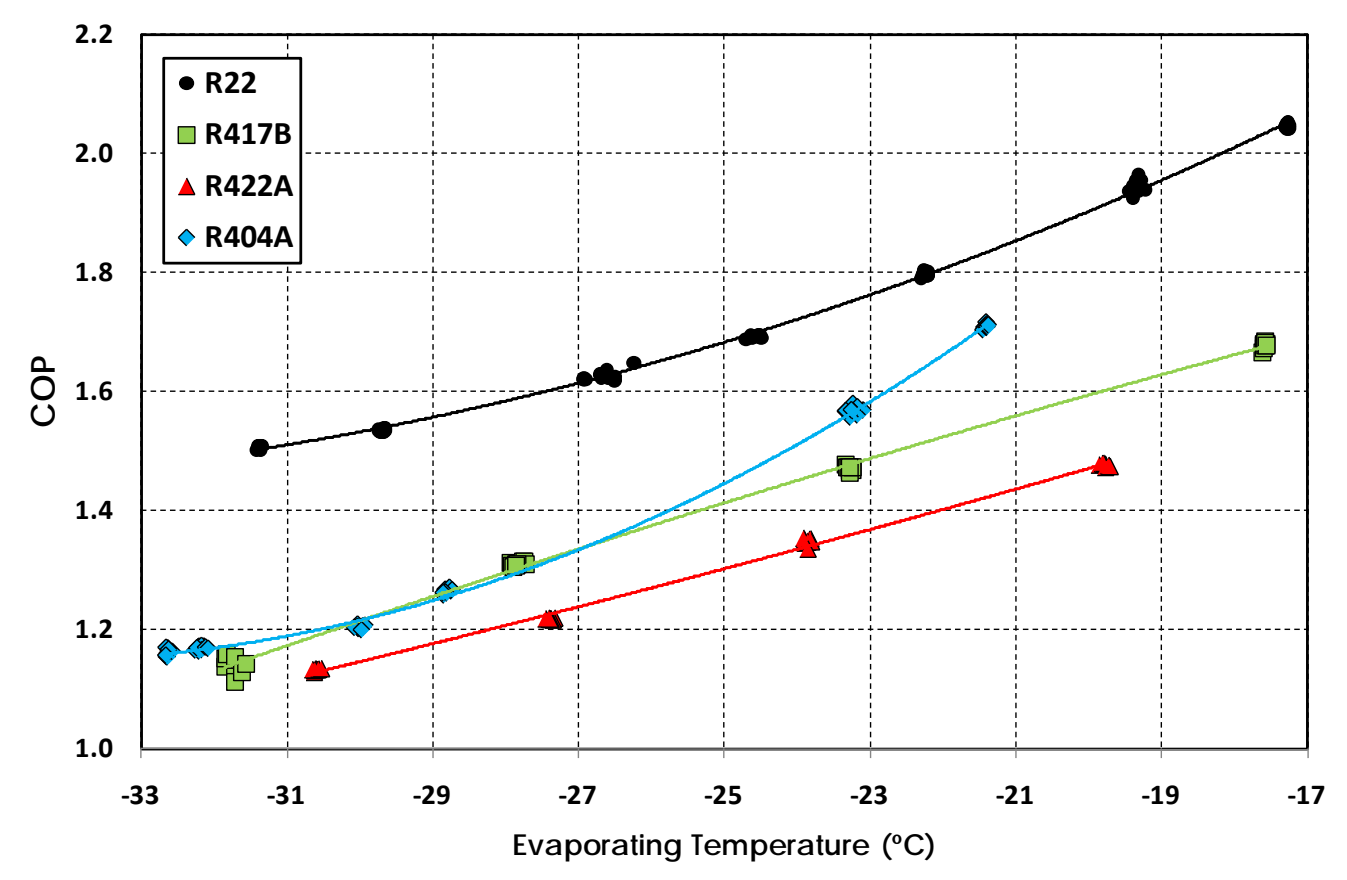

Figure 20. $\operatorname{COP}\left(T_{k}=40^{\circ} \mathrm{C}\right)$ 


\section{FIGURE CAPTIONS}

Figure 1. Mechanisms and some refrigerant options to substitute R22 in low temperature applications (Flohr and Meurer, 2009)

Figure 2. Pressure-enthalpy diagram of the R22 and the substitutes

Figure 3. Theoretical VCC of the ideal two-stage cycle $\left(T_{k}=40^{\circ} \mathrm{C}\right)$

Figure 4. Theoretical COP of the ideal two-stage cycle $\left(T_{k}=40^{\circ} \mathrm{C}\right)$

Figure 5. Schematic diagram of the plant

Figure 6. Evaporator refrigerant mass flow rate. $\left(T_{k}=40^{\circ} \mathrm{C}\right)$

Figure 7. Specific refrigerating effect $\left(T_{k}=40^{\circ} \mathrm{C}\right)$

Figure 8. Subcooler thermal effectiveness $\left(T_{k}=40^{\circ} \mathrm{C}\right)$

Figure 9. Cooling capacity $\left(T_{k}=40^{\circ} \mathrm{C}\right)$

Figure $10 . \operatorname{COP}\left(\mathrm{T}_{\mathrm{k}}=40^{\circ} \mathrm{C}\right)$ 


\section{TABLES CAPTIONS}

Table 1. Physical, environmental and safety characteristics of the refrigerants (Calm and Houranhan, 2007; Lemmon et al., 2007) 